\title{
Exploring the Environmental Manifestation of Types of Music on Reinforcing Mindfulness and Concurrent Calorie Intake
}

\section{Misba Hussain (D), Helen Egan, Rebecca Keyte and Michail Mantzios (D) \\ Department of Psychology, Birmingham City University, Birmingham, UK}

\begin{abstract}
Background: The role of music on energy intake is conflicting, and recent research has suggested a positive association between classical music listening and mindfulness. Objective: The purpose of the present study was to investigate the effect of music, specifically classical music on state mindfulness and calorie intake of energy-dense foods.

Method: One hundred participants were randomly assigned to either a classical, popular or no music condition, and were served a variety of sweet (i.e., chocolate and cookies) and savoury (i.e., crisps) energy-dense foods. Results: The results found no significant differences in state mindfulness, overall calorie intake, or intake of sweet foods across the three conditions. However, participants in the classical music condition did consume significantly less savoury food than those in the no music condition.
\end{abstract}

\section{Corresponding Author:}

Misba Hussain, Department of Psychology, Faculty of Business, Law and Social Sciences, Birmingham City University, The Curzon Building, 4 Cardigan Street, Birmingham B4 7BD, UK.

Email: Misba.Hussain@mail.bcu.ac.uk 
Conclusion: Playing classical music may be beneficial in reducing intake of savoury foods, but not through the association to changes in state mindfulness. Future research should explore extended sessions of music listening on state mindfulness and other experiential evaluations of mindfulness to conclude on the direct and indirect effects of music on sweet and savoury foods.

\section{Keywords}

Environment, music, eating behaviours, calorie intake, mindfulness

Eating behaviours in general can be influenced by external factors, such as the environmental stimuli (Wansink, 2004). For example, television viewing, presence of other people and ambience are all suggested to act as food intake regulators as they affect food choice, motivation to eat and meal duration (Braude \& Stevenson, 2014; Robinson \& Higgs, 2013; Wansink \& Van Ittersum, 2012). The construct of mindfulness has also been proposed to affect eating behaviours with research suggesting mindfulness is associated with lower caloric intake, reduced fat and sugar consumption, and smaller serving sizes (Arch et al., 2016; Beshara et al., 2013; Mantzios et al., 2018). Exploring strategies to promote healthier eating behaviours within the eating context of one's environment is becoming increasingly important when observing the sustainability of interventions and the worldwide prevalence of obesity (Arroyo-Johnson \& Mincey, 2016). Simply putting some music on may propose an effortless way of healthier and well regulated eating, and is worth exploring to propose additional methods of support.

Music is an element that is present in many public and private eating places, and the presence of music has been suggested to be associated with increased energy intake (Lock et al., 2016; Stroebele \& de Castro, 2006). Specifically, different features of music are suggested to distinctively affect eating behaviours (e.g., Karapetsa et al., 2015). For example, research within music genre indicates that classical music leads to a greater enjoyment in food (Novak et al., 2010), and research on music tempo suggests increased music speed leads to higher energy intake (e.g., Milliman, 1986; Roballey et al., 1985; Wansink \& Van Ittersum, 2012). However, at the same time, other researchers have not been able to replicate such findings, and have instead found no influence of music on energy intake (e.g., Mamalaki et al., 2017; Péneu, Mekhmoukh, Chapelot, Dalix, Airinei, Hercberg, \& Bellisle, 2009). The mechanisms behind such conflicting findings are not apparent, and appear to need exploring. 
Research has found that certain elements of music can have a calming or stimulating effect depending on the tempo or genre (Koelsch \& Siebel, 2005; Patel, 2003), which could explain the inconsistent findings observed in eating literature. For example, recent research has found a positive association between listening to classical music on a regular basis and mindfulness (Bell et al., 2016). Mindfulness is characterised as an awareness that emerges through purposefully paying attention to what is taking place in the present moment with a nonjudgmental attitude (Kabat-Zinn, 1990). Specifically, those who practice mindfulness through meditational exercises on average increase their predisposition to be mindful in daily life, which in effect has shown to contribute towards healthier eating behaviours across time (Dalen et al., 2010; Jordan et al., 2014; Kristeller, Wolever, \& Sheets, 2014). In general, there seems to be little research conducted on music and its effect on mindfulness; however, previous studies that have been conducted do suggest a possible association between the two, specifically regarding classical music (Bell et al., 2016). For example, similar to classical music, mindfulness practices are also suggested to have a calming effect amongst participants (e.g., Lauricella, 2014), and similar neurophysiology amongst those who regularly engage in mindfulness meditation and those who listen to classical music on a daily basis has also been found (Aoun et al., 2005; Hölzel, Carmody, Vangel, Congleton, Yerramsetti, Gard, \& Lazar, 2011; Vuilleumier, 2005). Furthermore, those who actively participate in music activities develop enhanced awareness of self and others, as well as improved listening and attention skills, components that are key in mindfulness practices (Auerbach \& Delport, 2018), and mindful eating practices (Dalen et al., 2010; Kristeller et al., 2014). Therefore, elements of mindfulness could potentially be developed through centring on music, specifically classical music.

It could be suggested mindfulness (or the lack of mindfulness) may be a contributing factor towards the conflicting findings on music and energy intake. Over recent years, mindfulness has been used as a intervention strategy in promoting healthier eating practices, such as, reduced food cravings, resisting energy-dense foods, and choosing healthier food options (e.g., Dutt et al., 2019; Jenkins \& Tapper, 2014; Mantzios et al., 2020). Furthermore, similar to classical music, mindfulness has shown to enhance the enjoyment of foods consumed (Arch et al., 2016; Hong et al., 2014). Research indicates that mindful attention can help reduce the temptations of consuming attractive, but unhealthy foods by viewing such simulations as mere mental events, and as a result assist in the gradual change of external to internal eating (Mantzios et al., 2019; Mantzios \& Giannou, 2014; Marchiori \& Papies, 2014). The majority of experimental studies that use mindfulness as a strategy in promoting healthier eating behaviours use body scan exercises or short audio recordings of mindful instructions (e.g., Jenkins \& Tapper, 2014; Jordan et al., 2014). Mantzios and Giannou (2018) proposed how mindfulness could be utilised to become short and effortless practices, and some research has focused on introducing brief and effortless 
interventions to enable adherence and embedment within one's lifestyle (Hussein, Egan, \& Mantzios, 2017; Mantzios \& Wilson, 2014a, 2014b, 2015). However, this study poses the question whether state mindfulness can be induced via a simple environmental change and the complete disengagement from any active interventions. Since previous studies have concluded that listening to music on a regular basis can promote mindfulness (e.g., Bell et al., 2016), and mindfulness has shown to be successful in encouraging healthier eating behaviours (e.g., Albert et al., 2010; Dutt et al., 2019), exploring exposure to classical music whilst being exposed to food is an initial pilot of exploring associations and proposals for future research.

The present study investigated whether briefly listening to music could induce a mindfulness state, and in effect, lead to a reduced consumption of energydense foods. It was hypothesised that state mindfulness would increase, and calorie intake from energy-dense foods would be lower when listening to classical music in comparison to popular music and no music, and correspondingly significantly differ in food consumption.

\section{Method}

\section{Participants}

One hundred participants ( 76 female, 21 male, 3 not-specified) were recruited via opportunity sampling from a university in West Midlands, United Kingdom. The opportunity sampling recruitment involved issuing a brief overview of the study to any potential participants, and those who expressed interest were then provided with further instructions (see Procedure). Participants did not receive any compensation for their involvement in the study. Participants had an average BMI of $M=21.72(S D=10.77)$ and an age of $M=26.18(S D=13.02)$. and their self-identified ethnicities were: White or White British $(n=65)$, Black African or Caribbean $(n=7)$, Asian $(n=20)$, Middle Eastern $(n=2)$, and mixed ethnicity $(n=6)$. The present study was approved by the University ethical committee, and informed consent was gained from all participants.

Eligibility. Due to the nature of the study (i.e., presence of food), participants were informed via an information sheet and consent form that they were not eligible to participate if they had been diagnosed with an eating disorder or if they had any food allergies/intolerances.

\section{Experimental conditions}

Participants were randomly assigned to one of three conditions: classical music $(n=33$; female $=24$, male $=7$, not-specified $=2)$, popular music $(n=33$; female $=29$, male $=4)$, and no music $(n=34 ;$ female $=23$, male $=10$, 
not-specified =1). The music tempo in the two conditions was estimated to be similarly slow, and the music in the classical condition was chosen from the "50 Greatest Pieces of Classic Music" playlist because of its genre, and lasted a total of 7 mins. The choice of songs used for the popular music condition were based on their popularity, and were therefore chosen from the "Official UK Top 40 Singles Chart" during the period of Spring 2018, and lasted a total of 7 mins 28 s.

\section{Self-report measurements}

Demographics. To assess demographics, participants were asked questions regarding their gender, age, height, weight and ethnicity.

Baseline hunger. To assess hunger, participants were asked "How hungry do you feel right now?" with responses ranging from 1 (not at all) to 5 (extremely hungry).

Taste test. In a bogus taste test, participants were asked to rate the foods in front of them (e.g., "How much did you like the taste of the chocolate minstrels?") with responses ranging from 1 (not at all) to 5 (extremely). The results of the bogus taste test were also used to assess participants' likeability of the foods.

State mindfulness scale (SMS;Tanay and Bernstein, 2013). The SMS is a 21 item tool that reflects on traditional and contemporary models of mindfulness. It includes items such as "I felt that I was experiencing the present moment fully" and "I felt aware of what was happening inside of me". Responses range from 1 (not at all) to 5 (very well), with total scores varying from 21 to 105 . In order to get both pre and post measures of the SMS, participants completed the SMS measure before and after the introduction of music (or no music) and food.

Three-factor eating questionnaire (TFEQ; Karlsson, Persson, Sjöström, \& Sullivan, 2000). To control for any eating behaviour patterns that could potentially affect the results, the TFEQ was administrated. The TFEQ is an 18 item tool that consists of three subscales: restraint eating, uncontrolled eating and emotional eating. Sample items include "I deliberately take small helpings as a means of controlling my weight" (i.e., emotional eating) and "I am always hungry so it is hard for me to stop eating before I finish the food on my plate" (i.e., uncontrolled eating). Responses range from 1 (definitely false) to 4 (definitely true), with overall scores ranging from 18 to 76 .

\section{Food}

Participants were served with both sweet and savoury high energy-dense foods in order to cater for differences in food preferences and ensure food variety. Participants were presented with Walkers salted crisps (132 kcal/25g), 
Table I. Number of participants who finished consuming each snack across classical music, popular music and no music conditions.

\begin{tabular}{llll}
\hline & $\begin{array}{c}\text { Classical music } \\
\text { condition }(n=33)\end{array}$ & $\begin{array}{c}\text { Popular music } \\
\text { condition }(n=33)\end{array}$ & $\begin{array}{c}\text { No music } \\
\text { condition }(n=34)\end{array}$ \\
\hline Crisps & 0 & 3 & 6 \\
Chocolate & 9 & 3 & 2 \\
Cookies & 0 & $\mathrm{I}$ & 3 \\
Crisps and chocolate & 3 & $\mathrm{I}$ & 3 \\
Crisps and cookies & 0 & 0 & $\mathrm{I}$ \\
Chocolate and cookies & 0 & $\mathrm{I}$ & $\mathrm{I}$ \\
Crisps, chocolate & 0 & 0 & $\mathrm{I}$ \\
$\quad$ & & & \\
\hline
\end{tabular}

Galaxy chocolate minstrels (225 kcal/45g) and Oreo cookies (212 kcal/45.2g), and they were able to eat as much or as little as they preferred. Participants were not required to try all three snacks, but were given the option to do so. All portions served were based on standard UK portion sizes, and all food products were sourced from UK Tesco stores and were presented on individual bowls $(15 \mathrm{~cm} \times 15 \mathrm{~cm} \times 8 \mathrm{~cm})$. Food consumption was explored in order to identify any possible ceiling effect, and as Table 1 shows, no effect was found.

\section{Procedure}

The study was advertised as an experiment investigating the effect of environmental stimuli on taste perception. Experimental sessions took place between $12 \mathrm{pm}$ and $4 \mathrm{pm}$ lasting approximately 25 minutes. Upon entering the lab, participants received an information sheet, and after providing informed consent, they were seated in individual cubicles. Participants height and weight was measured using a stadiometer and a digital scale, and they were asked to complete demographic questions, a hunger scale and a state mindfulness scale. Next, the experimenter provided participants with three bowls of food containing crisps, chocolates, and cookies. Participants in both the classic and popular music conditions were instructed to listen to music on their computer media player using their headphones, and consume as much or as little of the food they wanted in order to judge the taste of the food products. Whilst participants in the no music condition were simply instructed to eat as much or as little food as they wanted in order to judge the taste of the food. In order to keep the experiment relevant to the advertisement of the study (i.e., environmental stimuli on taste perception), water was not accompanied with the food. After either listening to classical music, popular music, or having no music, participants filled out a bogus taste test. Those who did not eat any one of the snacks could simply select "Did Not Eat X", and they then completed another measure of the state 
mindfulness scale. Finally, participants were debriefed and thanked for their participation.

\section{Data analysis}

Calorie intake was determined for food products by calculating the difference in weight of each bowl between the start and end of experimental sessions, and multiplying the weight consumed by the calorie density of each food product. Chi square was used to account for differences in gender across conditions, and one way ANOVAs were carried out to test for differences across conditions in participants' baseline hunger, food likeability (i.e., crisps, chocolate and cookies), BMI, age, and eating behaviours including restraint, uncontrolled and emotional eating. A 3 X 2 ANOVA was planned to test whether a difference was observed in post state mindfulness scores across the three conditions. State mindfulness change was utilised to create a group that increased vs decreased throughout the music manipulations, and this was conducted by subtracting post state mindfulness scores with pre state mindfulness scores which created one score (i.e., "change score"), and those who decreased or increased on the change score were grouped in decrease and increase groups, respectively. $3 \mathrm{X} 2$ ANOVAs were conducted to explore the effect of state mindfulness change and music on participants' calorie intake. Baseline hunger, food likeability (i.e., crisps, chocolate and cookies) and participant characteristics were tested as covariates to assess whether they had any effect on the dependent variables. All analyses were conducted using SPSS v24.

\section{Results}

\section{Participant characteristics}

Chi Square analysis revealed that gender was equally distributed across the three conditions $\chi^{2}(6)=6.37, p=.38$. One way ANOVAs found no significant differences across conditions in participants' baseline hunger, food likeability (i.e., crisps, chocolate and cookies), BMI and eating behaviours including restraint, uncontrolled, and emotional eating: all $p>.12$. There was a significant difference in age, whereby age was lower in the popular music condition $(M=20.55$, $S D=7.37)$ than the classical music condition $(M=29.06, S D=14.24)$ and the no music condition $(M=28.85, S D=14.55)$ (see Table 2). Participants' baseline hunger, food likeability (i.e., chocolate and cookies), BMI, age and eating behaviours including restraint, uncontrolled and emotional eating were tested as covariates, and were found to have no significant effect on state mindfulness or on the caloric intake of the foods presented, and are thus not discussed further. 
Table 2. Measures of baseline hunger, food likeability and participants characteristics across classic music, popular music and no music conditions.

\begin{tabular}{lcccc}
\hline & $\begin{array}{c}M(S D)- \\
\text { classical music } \\
\text { condition }(n=33)\end{array}$ & $\begin{array}{c}M(S D)- \\
\text { popular music } \\
\text { condition }(n=33)\end{array}$ & $\begin{array}{c}M(S D)- \\
\text { no music } \\
\text { condition }(n=34)\end{array}$ & $p$ \\
\hline Baseline hunger & $1.81(.68)$ & $1.97(1.02)$ & $2.01(.86)$ & .18 \\
Crisps likeability & $2.79(2.25)$ & $2.33(2.15)$ & $3.06(2.07)$ & .38 \\
Chocolate likeability & $3.18(2.05)$ & $3.12(2.09)$ & $4.03(1.83)$ & .12 \\
Cookie likeability & $1.58(1.84)$ & $1.45(1.97)$ & $1.71(2.13)$ & .87 \\
BMI & $25.79(5.42)$ & $22.72(9.00)$ & $24.84(8.89)$ & .32 \\
Eating behaviours ${ }^{\mathrm{a}}$ & $41.45(11.29)$ & $41.24(9.77)$ & $42.32(7.80)$ & .89 \\
Restraint eating $^{\mathrm{b}}$ & $13.06(4.86)$ & $12.70(4.23)$ & $12.44(3.70)$ & .84 \\
Uncontrolled eating $^{\mathrm{b}}$ & $21.45(6.77)$ & $20.73(6.58)$ & $22.12(4.96)$ & .65 \\
Emotional eating $^{\mathrm{b}}$ & $6.94(3.15)$ & $7.81(3.14)$ & $7.76(2.81)$ & .42 \\
Age $^{\mathrm{c}}$ & $29.06(14.24)$ & $20.56(7.37)$ & $28.85(14.55)$ & .01 \\
\hline
\end{tabular}

Note. $M$ and $S D$ are used to represent mean and standard deviation, respectively.

${ }^{\mathrm{a}}$ Three Factor Eating Questionnaire.

bSubscales of Three Factor Eating Questionnaire.

$\mathrm{Age}^{\mathrm{c}}=$ Significant difference between conditions.

\section{State mindfulness}

A 3 (condition: classical music, popular music, no music) X 2 (time: pre, post) mixed design ANOVA was carried out to explore the effect of music on state mindfulness across the three conditions. There was no significant main effect of conditions $F(2,97)=1.89, p=.16$, no significant main effect of time $F(1$, $97)=.98, p=.32$, and no significant interaction between conditions and time $F(2,97)=.50, p=.60$ (see Table 2 ). Therefore, suggesting that exposure to classical music, popular music and no music had no significant effect on increasing (or decreasing) participants state mindfulness (see Table 3).

\section{Overall intake}

A 3 (condition: classical music, popular music, no music) X 2 (state mindfulness: decrease, increase) between group ANOVA was conducted to explore the effects of music and state mindfulness on participants overall calorie intake (i.e., crisps, chocolate, and cookies). There was no significant main effect of conditions $F(2$, $94)=1.33, p=.27$, no significant main effect of state mindfulness $F(1,94)=$ $1.75, p=.19$, and no significant interaction between conditions and state mindfulness $F(2,94)=.20, p=.82$. Therefore suggesting both music and state mindfulness had no significant effect on participants overall calorie intake (see Table 4). 
Table 3. Pre and post measures of state mindfulness scale across classical music, popular music and no music conditions.

\begin{tabular}{lll}
\hline & $M(S D)-$ pre & $M(S D)-$ post \\
\hline Classical music condition $(n=33)$ & $64.73(17.27)$ & $61.64(21.21)$ \\
Popular music condition $(n=33)$ & $68.33(18.68)$ & $69.12(17.94)$ \\
No music condition $(n=34)$ & $63.21(17.18)$ & $59.94(17.39)$ \\
\hline
\end{tabular}

Note. $M$ and SD are used to represent mean and standard deviation, respectively.

Table 4. Participants overall intake of sweet and savoury foods across classical, popular and no music conditions.

\begin{tabular}{lccc}
\hline & $\begin{array}{c}M(S D)- \\
\text { classical music } \\
\text { condition }(n=33)\end{array}$ & $\begin{array}{c}M(S D)- \\
\text { popular music } \\
\text { condition }(n=33)\end{array}$ & $\begin{array}{c}M(S D)- \\
\text { no music } \\
\text { condition }(n=34)\end{array}$ \\
\hline $\begin{array}{c}\text { Decrease state } \\
\text { mindfulness }\end{array}$ & $158.38(80.7 I)$ & $168.08(132.46)$ & $202.17(145.52)$ \\
$\begin{array}{c}\text { Increase state } \\
\text { mindfulness }\end{array}$ & $208.93(109.55)$ & $179.63(122.20)$ & $240.00(142.38)$ \\
\begin{tabular}{c} 
Total \\
\hline
\end{tabular} & $183.41(97.54)$ & $173.68(125.72)$ & $218.86(143.23)$ \\
\hline
\end{tabular}

Note. $M$ and SD are used to represent mean and standard deviation of calorie intake, respectively.

\section{Sweet food intake}

A 3 (condition: classical music, popular music, no music) X 2 (state mindfulness: decrease, increase) between group ANOVA was conducted to explore the effect of music and state mindfulness on participants calorie intake of sweet foods (i.e., chocolate and cookies). There was no significant main effect of conditions $F(2$, $94)=.52, p=.60$, no main effect of state mindfulness $F(1,94)=1.87, p=.17$, and no significant interaction between conditions and state mindfulness scores $F$ $(2,94)=.01, p=.99$. Therefore suggesting both music and state mindfulness had no significant effect on participants' intake of sweet foods (see Table 5).

\section{Savoury food intake}

A 3 (condition: classical music, popular music, no music) X 2 (state mindfulness: decrease, increase) between group ANOVA was conducted to explore the effect of music and state mindfulness on participants calorie intake of savoury food (i.e., crisps). There was a significant main effect of condition $F(2,94)=5.13$, $p .01, \eta_{\mathrm{p}}{ }^{2}=.10$. There was no main effect of state mindfulness $F(1,94)=.13$, $p=.72$, and no significant interaction between conditions and state mindfulness $F(2,94)=.97, p=.38$. 
Table 5. Participants intake of sweet foods across classical, popular and no music conditions.

\begin{tabular}{lccc}
\hline & $\begin{array}{c}M(S D)- \\
\text { classical music } \\
\text { condition }(n=33)\end{array}$ & $\begin{array}{c}M(S D)- \\
\text { popular music } \\
\text { condition }(n=33)\end{array}$ & $\begin{array}{c}\text { M (SD) - } \\
\text { no music } \\
\text { condition }(n=34)\end{array}$ \\
\hline $\begin{array}{c}\text { Decrease state } \\
\text { mindfulness }\end{array}$ & $141.06(69.79)$ & $119.94(94.78)$ & $139.37(\mid 40.76)$ \\
$\begin{array}{c}\text { Increase state } \\
\text { mindfulness }\end{array}$ & $171.31(82.43)$ & $145.32(115.72)$ & $172.07(82.43)$ \\
Total & $155.73(76.53)$ & $132.24(104.57)$ & $153.79(|3| .00)$ \\
\hline
\end{tabular}

Note. $M$ and SD are used to represent mean and standard deviation of calorie intake, respectively.

The covariate, likeability of crisps, had a significant effect on participants consumption of crisps $F(1,96)=11.41, p=.001, \eta_{\mathrm{p}}{ }^{2}=.11$. There was also a significant effect of music on participants consumption of crisps after controlling for the effect of likeability of crisps $F(2,96)=5.02, p=.01, \eta_{\mathrm{p}}{ }^{2}=.10$.

A Bonferroni pairwise comparison indicated that participants in the classical music condition consumed significantly less crisps $(M=27.26, S E=7.96$, $p=.01)$ than those in the no music condition $(M=62.68, S E=7.87)$. There was no significant difference found in the consumption of crisps between participants in the classical music condition and popular music condition $(M=44.32, S E=8.00, p=.40)$, or between participants in the no music condition and popular music condition $(p=.32)$ (see Table 6 ).

\section{Discussion}

The present study investigated whether briefly listening to classical music could induce an increase in state of mindfulness, and in effect, result in a reduced intake of energy-dense foods. Contrary to our hypotheses, the data showed that there were no significant differences in state mindfulness across classical music, popular music and no music conditions. There were also no significant differences found in the overall calorie intake of foods, or in the intake of sweets foods (i.e., chocolate and cookies) across the three conditions. However, participants in the classical music condition did consume significantly less savoury food (i.e., crisps) than those in the no music condition, even after controlling for the likeability of crisps. Thus, suggesting background music does not affect state mindfulness or intake of sweet foods, but playing classical music may be beneficial in reducing intake of savoury foods.

Prior research has suggested similarities in the mechanisms underlying mindful meditation and classical music listening (Angelucci et al., 2007; Holzel et al., 2011), and whilst the findings from the current study do not align with such literature, previous research has solely explored the long term effects of classical music listening on mindfulness (Bell et al., 2016). The music in the current study 
Table 6. Participants intake of savoury foods across classical, popular and no music conditions.

\begin{tabular}{llll}
\hline & $\begin{array}{c}\text { Classical music } \\
\text { condition }(n=33)\end{array}$ & $\begin{array}{c}\text { Popular music } \\
\text { condition }(n=33)\end{array}$ & $\begin{array}{c}\text { No music } \\
\text { condition }(n=34)\end{array}$ \\
\hline $\begin{array}{l}M(S D) \\
\text { Decrease state } \\
\text { mindfulness } \\
\begin{array}{l}\text { Increase state } \\
\text { mindfulness }\end{array}\end{array}$ & $18.32(33.76)$ & $48.14(50.02)$ & $62.80(50.67)$ \\
$\begin{array}{l}\text { Total } \\
M_{\text {adj }}(S E)\end{array}$ & $27.68(44.04)$ & $34.32(46.55)$ & $67.94(54.65)$ \\
Total & $27.26(7.96)$ & $41.44(48.12)$ & $65.07(51.71)$ \\
\hline
\end{tabular}

Note. $M$ and SD are used to represent mean and standard deviation of calorie intake, respectively. $M_{a d j}$ and $S E$ are used to represent adjusted mean and standard error of calorie intake by controlling likeability of crisps, respectively.

was played for 7 mins (classical music condition), which may not have been a sufficient amount of time to induce a state of mindfulness, and perhaps a slightly longer period of music listening may have led to a greater change in state mindfulness. That being said, state mindfulness did slightly decrease in the classic music condition, and moderately increase in the popular music condition. A potential reason for this could be that participants in the popular music condition may have liked the music more than participants in the classical music condition, which in turn may have led to other elements that may have influenced state mindfulness. For example, nostalgia (Sedikides \& Skowronski, 2020) and familiarity of the song (Barrett et al., 2010) may serve as a way of increasing mindfulness. When listening to a song that reminds someone of a positive (or negative) experience, their mind may wonder away for a moment, and they then return their attention back to the music that is playing; an element that replicated the notion of the self-regulation of attention that is described in mindfulness literature (Baer et al., 2004). However, the present did study did not conduct any assessments on music likeability, which could have indeed had an effect on the current results (Kantono et al., 2016). Future research exploring likeability, nostalgia and familiarity, as well as memories associated to the song may serve an enhanced and more tightly controlled experiment.

The non-significant differences in participants overall calorie intake across the classical music, popular music and no music conditions could be explained by the non-significant changes in state mindfulness scores. Although in the present study, it did appear that participants who increased in their state mindfulness after the music manipulations did exhibit a slightly (i.e., non-significant) greater intake of energy-dense foods than those who scored lower in state mindfulness; previous research has suggested mindfulness to be a key factor in 
promoting healthier eating behaviours. For example, findings have suggested participants who reported high levels of mindfulness are suggested to increase their intake of fruit and vegetables and reduce their calorie consumption of high energy-dense foods (Dutt et al., 2019). Research suggests mindfulness can minimise automatic and inattentive reactions around food, and bring back the focus to what one is eating (see Mantzios \& Wilson, 2015). On the other hand, Mantzios and Wilson (2015) proposed that mindfulness interventions may need to be specific to the eating experience, and it may be the case that mindfulness induction may need to co-occur with the eating experience, and not one being subsequent to the other. For now, we can conclude that the nonsignificant changes in state mindfulness influence any interpretations on eating and overall calorie intake across conditions.

Despite state mindfulness not significantly increasing, participants in the classical music condition did consume significantly less savoury food than those in the no music condition. Previous research has found that different elements of music, such as genre, volume, tempos, pitches and likeability can have an effect on the perception (i.e., pleasantness and enjoyments) of foods, specifically sweet foods (Fiegel et al., 2019), which could offer another level of explanation of present findings. However, research has not yet directly explored the effect of music on savoury vs sweet foods, which could be another avenue for future research. For example, the majority of other research conducted on music and eating behaviours has explored variables such as meal duration and overall amount of food consumed, (e.g., Kaiser et al., 2016). The possibility that the effect of music, specifically classical music may differ between savoury and sweet foods could provide a possible explanation for the conflicting findings on music and energy intake, the association to mindfulness, and the potential differences between meals and snacks.

\section{Limitations and future research}

There are some limitations within the current study that require further discussion. Firstly, the current study was conducted in a controlled laboratory setting, suggesting a lack of ecological validity. Future studies should conduct similar research in field settings to investigate whether any differences are apparent in mindfulness and calorie intake.

Furthermore, there was no assessment conducted on any chewing sounds that participants may have experienced whilst eating with their headphones. Previous studies have suggested that listening to oneself chew could affect eating behaviours in regards to enjoyment and energy intake (Elder \& Mohr, 2016). Moreover, although hunger did not appear to have any effect on the current findings, the study was conducted between $12 \mathrm{pm}$ and $4 \mathrm{pm}$. As such, it could be possible that those who did not eat their lunch prior to the experimental session may have consumed more than those who did eat lunch. Therefore, any future 
research should control for such measure as a means of enhancing the development of this research.

Additionally, the current study did not investigate the effects of different tempos and noise levels of music on state mindfulness or on calorie intake of energy-dense foods, and the presence of different tempos and noise levels may have led to contrasting findings. For example, listening to music of increased tempo and noise level may have led participants to be less mindful, and in effect, increase their intake (McCarron \& Tierney, 1989); whilst the presence of reduced tempo and noise level may have led to participants to be more mindful, and in effect, potentially reduce their intake (McElrea \& Standing, 1992). The present study did use music with similar estimations of tempos between the two music conditions; future research should investigate the effects of different tempos and noise levels, as well as pleasant and unpleasant music on participants' state mindfulness and calorie intake of energy-dense foods.

Finally, the sample within the current study was small, and consisted predominantly of healthy females. Future research should use a larger and diverse sample representing both genders and varied BMI.

\section{Conclusion}

The findings from the present pilot study suggest that listening to classical music or popular music does not affect mindfulness any differently than no music. However, playing classical music may be beneficial in reducing intake of savoury foods. Protecting the fiscal health of public services whilst also enhancing health behaviours may be achieved through detailing the relationship between mindfulness and music as this can be achieved through minimal interventions with high adherence, and added to existing clinical practices without additional costs to national health services.

\section{Declaration of Conflicting Interests}

The author(s) declared no potential conflicts of interest with respect to the research, authorship, and/or publication of this article.

\section{Funding}

The author(s) received no financial support for the research, authorship, and/or publication of this article.

\section{ORCID iDs}

Misba Hussain (D) https://orcid.org/0000-0002-7712-0559

Michail Mantzios (D) https://orcid.org/0000-0002-7476-3559 


\section{References}

Alberts, H., Mulkens, S., Smeets, M., \& Thewissen, R. (2010). Coping with food cravings. Investigating the potential of a mindfulness-based intervention. Appetite, 55(1), 160-163. https://doi.org/10.1016/j.appet.2010.05.044

Angelucci, F., Fiore, M., Ricci, E., Padua, L., Sabino, A., \& Tonali, P. (2007). Investigating the neurobiology of music: Brain-derived neurotrophic factor modulation in the hippocampus of young adult mice. Behavioural Pharmacology, 18(5-6), 491-496. https://doi.org/10.1097/fbp.0b013e3282d28f50

Aoun, P., Jones, T., Shaw, G., \& Bodner, M. (2005). Long-term enhancement of maze learning in mice via a generalized Mozart effect. Neurological Research, 27(8), 791-796. https://doi.org/10.1179/016164105x63647

Arch, J., Brown, K., Goodman, R., Della Porta, M., Kiken, L., \& Tillman, S. (2016). Enjoying food without caloric cost: The impact of brief mindfulness on laboratory eating outcomes. Behaviour Research and Therapy, 79, 23-34. https://doi.org/10.1016/ j.brat.2016.02.002

Arroyo-Johnson, C., \& Mincey, K. (2016). Obesity epidemiology worldwide. Gastroenterology Clinics of North America, 45(4), 571-579. https://doi.org/10.1016/j. gtc.2016.07.012

Auerbach, C., \& Delport, A. (2018). Developing mindfulness in children through participation in music activities. South African Journal of Childhood Education, 8(1), 1-7. https://doi.org/10.4102/sajce.v8i1.519

Baer, R., Smith, G., \& Allen, K. (2004). Assessment of mindfulness by self-report. Assessment, 11(3), 191-206. https://doi.org/10.1177/1073191104268029

Banna, J., Richards, R., \& Brown, L. (2017). College students' perceived differences between the terms real meal, meal, and snack. Journal of Nutrition Education and Behaviour, 49(3), 228.e1-235.e1. https://doi.org/10.1016/j.jneb.2016.11.001

Barrett, F., Grimm, K., Robins, R., Wildschut, T., Sedikides, C., \& Janata, P. (2010). Music-evoked nostalgia: Affect, memory, and personality. Emotion, 10(3), 390-403. https://doi.org/10.1037/a0019006

Bell, T., McIntyre, K., \& Hadley, R. (2016). Listening to classical music results in a positive correlation between spatial reasoning and mindfulness. Psychomusicology: Music, Mind, and Brain, 26(3), 226-235. https://doi.org/10.1037/pmu0000139

Beshara, M., Hutchinson, A., \& Wilson, C. (2013). Does mindfulness matter? Everyday mindfulness, mindful eating and self-reported serving size of energy dense foods among a sample of South Australian adults. Appetite, 67, 25-29. https://doi.org/10. 1016/j.appet.2013.03.012

Braude, L., \& Stevenson, R. (2014). Watching television while eating increases energy intake. Examining the mechanisms in female participants. Appetite, 76, 9-16. https:// doi.org/10.1016/j.appet.2014.01.005

Dalen, J., Smith, B., Shelley, B., Sloan, A., Leahigh, L., \& Begay, D. (2010). Pilot study: Mindful eating and living (MEAL): Weight, eating behavior, and psychological outcomes associated with a mindfulness-based intervention for people with obesity. Complementary Therapies in Medicine, 18(6), 260-264. https://doi.org/10.1016/j.ctim.2010.09.008

De La Cruz, O., \& Rodríguez-Carvajal, R. (2014). Mindfulness and music: A promising subject of an unmapped field. International Journal of Behavioral Research \& Psychology, 2(3), 27-35. https://doi.org/10.19070/2332-3000-140006 
Dutt, S., Keyte, R., Egan, H., Hussain, M., \& Mantzios, M. (2019). Healthy and unhealthy eating amongst stressed students: Considering the influence of mindfulness on eating choices and consumption. Health Psychology Report, 7(2), 113-120. https:// doi.org/10.5114/hpr.2019.77913

Elder, R., \& Mohr, G. (2016). The crunch effect: Food sound salience as a consumption monitoring cue. Food Quality and Preference, 51, 39-46. https://doi.org/10.1016/j. foodqual.2016.02.015

Fiegel, A., Childress, A., Beekman, T., \& Seo, H. (2019). Variations in food acceptability with respect to pitch, tempo, and volume levels of background music. Multisensory Research, 32(4-5), 319-346. https://doi.org/10.1163/22134808-20191429

Hendrickson, K., \& Rasmussen, E. (2013). Effects of mindful eating training on delay and probability discounting for food and money in obese and healthy-weight individuals. Behaviour Research and Therapy, 51(7), 399-409. https://doi.org/10.1016/j.brat. 2013.04.002

Hölzel, B., Carmody, J., Vangel, M., Congleton, C., Yerramsetti, S., Gard, T., \& Lazar, S. (2011). Mindfulness practice leads to increases in regional brain gray matter density. Psychiatry Research: Neuroimaging, 191(1), 36-43. https://doi.org/10.1016/j. pscychresns.2010.08.006

Hong, P. Y., Lishner, D. A., \& Han, K. H. (2014). Mindfulness and eating: An experiment examining the effect of mindful raisin eating on the enjoyment of sampled food. Mindfulness, 5(1), 80-87. https://doi.org/10.1007/s12671-012-0154-x

Hussein, M., Egan, H., \& Mantzios, M. (2017). Mindful construal diaries: A less anxious, more mindful, and more self-compassionate method of eating. SAGE Open, 7(2), 215824401770468. https://doi.org/10.1177/2158244017704685

Jenkins, K., \& Tapper, K. (2014). Resisting chocolate temptation using a brief mindfulness strategy. British Journal of Health Psychology, 19(3), 509-522. https://doi.org/10. 1111/bjhp. 12050

Jeon, K., Lee, O., Kim, H., \& Han, S. (2011). Comparison of the dietary intake and clinical characteristics of obese and normal weight adults. Nutrition Research and Practice, 5(4), 329. https://doi.org/10.4162/nrp.2011.5.4.329

Jordan, C., Wang, W., Donatoni, L., \& Meier, B. (2014). Mindful eating: Trait and state mindfulness predict healthier eating behavior. Personality and Individual Differences, 68, 107-111. https://doi.org/10.1016/j.paid.2014.04.013

Kabat-Zinn, J. (1982). An outpatient program in behavioral medicine for chronic pain patients based on the practice of mindfulness meditation: Theoretical considerations and preliminary results. General Hospital Psychiatry, 4(1), 33-47. https://doi.org/10. 1016/0163-8343(82)90026-3

Kabat-Zinn, J. (1990). Full catastrophe living: Using the wisdom of your body and mind to face stress, pain and illness. Delacourt.

Kaiser, D., Silberberger, S., Hilzendegen, C., \& Stroebele-Benschop, N. (2016). The influence of music type and transmission mode on food intake and meal duration: An experimental study. Psychology of Music, 44(6), 1419-1430. https://doi.org/10. $1177 / 0305735616636207$

Kantono, K., Hamid, N., Shepherd, D., Yoo, M., Carr, B., \& Grazioli, G. (2016). The effect of background music on food pleasantness ratings. Psychology of Music, 44(5), 1111-1125. https://doi.org/10.1177/0305735615613149 
Karapetsa, A. A., Karapetsas, A. V., Maria, B., \& Laskaraki, I. R. M. (2015). The role of music on eating behavior. Encephalos, 52, 59-63.

Karlsson, J., Persson, L. O., Sjöström, L., \& Sullivan, M. (2000). Psychometric Properties and Factor Structure of the Three-Factor Eating Questionnaire (TFEQ) in Obese Men and Women. Results FROM THE Swedish Obese Subjects (SOS) Study. International Journal of Obesity and Related Metabolic Disorders : journal of the International Association for the Study of Obesity, 24(12), 1715-1725. https://doi.org/10.1038/sj. ijo.0801442 11126230

Koelsch, S., \& Siebel, W. (2005). Towards a neural basis of music perception. Trends in Cognitive Sciences, 9(12), 578-584. https://doi.org/10.1016/j.tics.2005.10.001

Kristeller, J., Wolever, R., \& Sheets, V. (2014). Mindfulness-based eating awareness training (MB-EAT) for binge eating: A randomized clinical trial. Mindfulness, 5(3), 282-297. https://doi.org/10.1007/s12671-012-0179-1

Lauricella, S. (2014). Mindfulness Meditation with Undergraduates in Face-TO-Face and Digital Practice: A Formative Analysis. Mindfulness, 5(6), 682-688. https://doi.org/ 10.1007/s12671-013-0222-X

Lock, C., Brindal, E., Hendrie, G., \& Cox, D. (2016). Contextual and environmental influences on reported dietary energy intake at evening eating occasions. Eating Behaviours, 21, 155-160. https://doi.org/10.1016/j.eatbeh.2016.03.012

Mamalaki, E., Zachari, K., Karfopoulou, E., Zervas, E., \& Yannakoulia, M. (2017). Presence of music while eating: Effects on energy intake, eating rate and appetite sensations. Physiology \& Behaviour, 168, 31-33. https://doi.org/10.1016/j.physbeh.2016.10.019

Mantzios, M., \& Wilson, J. (2014b). Making Concrete Construals Mindful: A Novel Approach for Developing Mindfulness and Self-Compassion to Assist Weight Loss. Psychology \& Health, 29(4), 422-441. https://doi.org/10.1080/08870446.2013.863883 24215123

Mantzios, M., Egan, H., \& Asif, T. (2019). A randomised experiment evaluating the mindful raisin practice as a method of reducing chocolate consumption during and after a mindless activity. Journal of Cognitive Enhancement, 4, 250-257. https://doi. org/10.1007/s41465-019-00159-y

Mantzios, M., Egan, H., Hussain, M., Keyte, R., \& Bahia, H. (2018). Mindfulness, selfcompassion, and mindful eating in relation to fat and sugar consumption: An exploratory investigation. Eating and Weight Disorders-Studies on Anorexia, Bulimia and Obesity, 23(6), 833-840. https://doi.org/10.1007/s40519-018-0548-4

Mantzios, M., \& Giannou, K. (2014). Group vs. single mindfulness meditation: Exploring avoidance, impulsivity, and weight management in two separate mindfulness meditation settings. Applied Psychology: Health and Well-Being, 6(2), 173-191. https://doi.org/10.1111/aphw.12023

Mantzios, M., \& Giannou, K. (2018). A real-world application of short mindfulnessbased practices: A review and reflection of the literature and a practical proposition for an effortless mindful lifestyle. American Journal of Lifestyle Medicine, 13(6), 520-525. https://doi.org/10.1177/1559827618772036

Mantzios, M., Skillett, K., \& Egan, H. (2020). Examining the effects of two mindful eating exercises on chocolate consumption. European Journal of Health Psychology, 26(4), 120-128. https://doi.org/10.1027/2512-8442/a000040 
Mantzios, M., \& Wilson, J. (2014a). Exploring the relationship between worry and impulsivity in military recruits: The role of mindfulness and self-compassion as potential mediators. Stress and Health, 30(5), 397-404. https://doi.org/10.1002/smi.2617

Mantzios, M., \& Wilson, J. (2015). Exploring mindfulness and mindfulness with selfcompassion-centered interventions to assist weight loss: Theoretical considerations and preliminary results of a randomized pilot study. Mindfulness, 6(4), 824-835. https://doi.org/10.1007/s12671-014-0325-z

Marchiori, D., \& Papies, E. (2014). A brief mindfulness intervention reduces unhealthy eating when hungry, but not the portion size effect. Appetite, 75, 40-45. https://doi. org/10.1016/j.appet.2013.12.009

McCarron, A., \& Tierney, K. (1989). The effect of auditory stimulation on the consumption of soft drinks. Appetite, 13(2), 155-159. https://doi.org/10.1016/0195-6663(89)90112-8

McElrea, H., \& Standing, L. (1992). Fast music causes fast drinking. Perceptual and Motor Skills, 75(2), 362-362. https://doi.org/10.2466/pms.1992.75.2.362

Milliman, R. (1986). The influence of background music on the behavior of restaurant patrons. Journal of Consumer Research, 13(2), 286. https://doi.org/10.1086/209068

Novak, C., La Lopa, J., \& Novak, R. (2010). Effects of sound pressure levels and sensitivity to noise on mood and behavioral intent in a controlled fine dining restaurant environment. Journal of Culinary Science \& Technology, 8(4), 191-218. https://doi.org/ $10.1080 / 15428052.2010 .535756$

Ogden, J., Wood, C., Payne, E., Fouracre, H., \& Lammyman, F. (2018). 'Snack' versus 'meal': The impact of label and place on food intake. Appetite, 120, 666-672. https:// doi.org/10.1016/j.appet.2017.10.026

Patel, A. (2003). Language, music, syntax and the brain. Nature Neuroscience, 6(7), 674-681. https://doi.org/10.1038/nn1082

Péneau, S., Mekhmoukh, A., Chapelot, D., Dalix, A., Airinei, G., Hercberg, S., \& Bellisle, F. (2009). Influence of environmental factors on food intake and choice of beverage during meals in teenagers: A laboratory study. British Journal of Nutrition, 102(12), 1854-1859. https://doi.org/10.1017/s0007114509991280

Prazak, M., Critelli, J., Martin, L., Miranda, V., Purdum, M., \& Powers, C. (2011). Mindfulness and its role in physical and psychological health. Applied Psychology: Health and Well-Being, 4(1), 91-105. https://doi.org/10.1111/j.1758-0854.2011.01063.x

Roballey, T. C., McGreevy, C., Rongo, R. R., Schwantes, M. L., Steger, P. J., Wininger, M. A., \& Gardner, E. B. (1985). The effect of music on eating behavior. Bulletin of the Psychonomic Society, 23(3), 221-222. https://doi.org/10.3758/BF03329832

Robinson, E., \& Higgs, S. (2013). Food choices in the presence of 'healthy' and 'unhealthy' eating partners. British Journal of Nutrition, 109(4), 765-771. https:// doi.org/10.1017/s0007114512002000

Sedikides, C., \& Skowronski, J. (2020). In human memory, good can be stronger than bad. Current Directions in Psychological Science, 29(1), 86-91. https://doi.org/10.1177/ 0963721419896363

Stroebele, N., \& de Castro, J. (2006). Listening to music while eating is related to increases in people's food intake and meal duration. Appetite, 47(3), 285-289. https://doi.org/10.1016/j.appet.2006.04.001 
Tanay, G., \& Bernstein, A. (2013). State Mindfulness Scale (SMS): development and Initial Validation. Psychological Assessment, 25(4), 1286-1299. https://doi.org/ 10.1037/a0034044 24059475

Tang, Y., Ma, Y., Wang, J., Fan, Y., Feng, S., \& Lu, Q, Yui, Q., Sui, D., Rothbart, M.K., Fan, M., \& Posner, M.I . (2007). Short-term meditation training improves attention and self-regulation. Proceedings of the National Academy of Sciences, 104(43), 17152-17156. https://doi.org/10.1073/pnas.0707678104

Vuilleumier, P. (2005). How brains beware: Neural mechanisms of emotional attention. Trends in Cognitive Sciences, 9(12), 585-594. https://doi.org/10.1016/j.tics.2005.10.011

Wansink, B. (2004). Environmental factors that increase the food intake and consumption volume of unknowing consumers. Annual Review of Nutrition, 24(1), 455-479. https://doi.org/10.1146/annurev.nutr.24.012003.132140

Wansink, B., \& van Ittersum, K. (2012). Fast food restaurant lighting and music can reduce calorie intake and increase satisfaction. Psychological Reports, 111(1), 228-232. https://doi.org/10.2466/01.pr0.111.4.228-232

\section{Author Biographies}

Misba Hussain is a doctoral student at Birmingham City University exploring mindful eating interventions.

Rebecca Keyte is a lecturer in Health Psychology interested in various health behaviours and interventions.

Helen Egan is a reader in Health Psychology interested in various health behaviours and interventions.

Michail Mantzios is a reader in Health Psychology interested in various health behaviours and health interventions. He is also the lead supervisor assigned to Miss Hussain for her doctoral research 